\title{
Feeding, oviposition and survival of overwintered rice water weevil (Coleoptera: Curculionidae) adults in response to nitrogen fertilization of rice at seedling stage
}

\author{
Mingxing JIANG and Jiaan ChenG* \\ Institute of Applied Entomology, Zhejiang University; Hangzhou 310029, P. R. China \\ (Received 26 December 2002; Accepted 19 July 2003)
}

\begin{abstract}
Overwintered adults of the rice water weevil, Lissorhoptrus oryzophilus Kuschel, were used to examine the impacts of nitrogen $(\mathrm{N})$ fertilization on their feeding, oviposition and survival. Rice plants (cultivar Shanyou 63) were fertilized with urea at 20 days after sowing at rates $0,30,60,90$, and $120 \mathrm{kgN} / \mathrm{ha}$, respectively. Plants were initially used the day after fertilization to determine adult performance, and used at 3, 9 and 16 days after transplantation (23, 29 and 36 days old, respectively) to test adult feeding and oviposition preference. Feeding, oviposition period, fecundity and survival duration increased significantly as fertilization increased from 30 to $60 \mathrm{kgN} / \mathrm{ha}$, and from 60 to $90 \mathrm{kgN} / \mathrm{ha}$ (except for fecundity), while they no longer increased significantly as fertilization increased further to $120 \mathrm{kgN} / \mathrm{ha}$. When provided with 29-d-old plants, adults preferred to feed on the plants fertilized at $60 \mathrm{kgN} / \mathrm{ha}$ rather than on those fertilized at higher levels, while for 36-d-old plants, the results were strikingly reversed. On 23-d-old plants, adults preferred to deposit eggs on those fertilized at $60 \mathrm{kgN} / \mathrm{ha}$; on 29- and 36-d-old plants, however, plants fertilized at 90 and $120 \mathrm{kgN} / \mathrm{ha}$ were significantly more preferred for oviposition.
\end{abstract}

Key words: Lissorhoptrus oryzophilus; rice; nitrogen fertilization; feeding; oviposition

\section{INTRODUCTION}

The rice water weevil, Lissorhoptrus oryzophilus Kuschel, has spread to at least ten provinces in China since it was first discovered in 1988 (Shang et al., 1998). Only parthenogenetic females occur in this country (Sun and Mao, 1996). In Zhejiang, the weevil has currently become one of the important insect pests of rice (Lin and Zhao, 1998). Two generations generally occur per year in this area but only the first one, which attacks rice in the first cropping season (late-April to late-July), is economically important (Zhai et al., 1997, 1999). Adult weevils overwinter in diapause at the base of many perennial grasses on local hills, levees, field margins, and other uncultivated areas (Zhai, 1996). In late spring, as mean daily temperature rises to about $15^{\circ} \mathrm{C}$ adults begin to feed on grasses in overwintering sites, and after flight muscles develop they gradually move to seedling beds and transplanted paddies (2nd half April to mid-May) (Zhai, 1996; Lin et al., 1997). Adults feed on rice leaves leaving longitudinal scars, and lay eggs in tissues of leaf sheaths under water; larvae feed on rice roots, resulting in weakened plant growth and subsequent yield loss.

Because nitrogen levels in plant tissues are generally a limiting resource for herbivores, increased nitrogen is often accompanied by enhanced growth, survival and fecundity of phytophagous insects (McNeill and Southwood, 1978). Increased occurrence and damage due to elevated nitrogen fertilization have been widely reported for major rice insect pests, especially rice stem borers and leaffolders (Ho and Kibuka, 1983; Rekhi et al., 1985; Thakur and Mishra, 1989; Dhandapani et al., 1990; Samalo et al., 1990; Sudhakar et al., 1993; Chander, 1999). These studies demonstrated the great potential for reducing these pests by optimizing nitrogen fertilization. For the rice water weevil, however, little is known in this area.

In most areas of China where the rice water weevil occurs, applications of synthetic-organic insecticide are presently the only effective method practically used for its control. In Zhejiang, chemical insecticides are sprayed normally between the

\footnotetext{
* To whom correspondence should be addressed at: E-mail: jacheng@zju.edu.cn
} 
emergence of seedlings and 1 week after transplantation with aims at reducing the numbers of adults (Lin and Zhao, 1998). This, however, should be avoided because using chemical insecticides at early stages of rice growth would probably disrupt natural enemies and subsequently induce serious outbreaks of other insect pests at later stages (Holt et al., 1992; Banerjee, 1996; Settle et al., 1996; Zhu, 1999). Therefore, other control tactics including cultural approaches are to be developed for the weevil to reduce insecticide uses at early rice stages.

The objectives of this study were to determine the relationships between adult feeding and oviposition of L. oryzophilus and the level of nitrogen fertilization to rice plants, and to evaluate the potential for reducing nitrogen fertilizer use as a control approach for this pest.

\section{MATERIALS AND METHODS}

Plants and fertilization treatments. Shanyou 63, a widely grown rice cultivar in China, was used in the experiments. Seeds were sown in early April in a screenhouse, and covered by a transparent plastic film to facilitate plant growth. At 8 days after sowing (2-leaf stage), urea $\left(\mathrm{CO}\left(\mathrm{NH}_{2}\right)_{2}\right.$, $46.7 \% \mathrm{~N}$ ) was applied at a rate $30 \mathrm{kgN} / \mathrm{ha}$. Twentyd-old seedlings with nearly identical plant height were transplanted in lines into cement plots in the screenhouse, with four plants per hill; a distance of $15 \mathrm{~cm}$ was kept between lines and $15 \mathrm{~cm}$ between hills within lines. Plants were then treated with urea at five levels (treatments): 0, 30, 60, 90 and $120 \mathrm{kgN} / \mathrm{ha}$, respectively. All of the clods used for seedling production and transplantation were collected from a rice field at Huajiachi campus, Zhejiang University.

Insects. Two groups of overwintered L. oryzophilus adults were collected from Yueqing, Zhejiang. The first group was collected from overwintering sites in late-March, when their spring feeding had initiated slightly. These weevils were stored in plastic cups containing soils with moistened withered grass leaves covering the surface, and kept beside a window of the laboratory until used. The second group was collected in late-April from a grass Imperata cylindrica (L.) Beauv. var. mojor (Nees) C. E. Hubb. on a hill near rice paddies; ovarian dissection indicated that $27 \%$ of these adults were at the previtellogenic stage while the others had not initiated reproductive development. I. cylindrica var. mojor has been known as one of the important host plants for overwintered adults before they infest rice (Jiang and Cheng, 2003).

Feeding and oviposition performance experiment. The day after fertilization treatment, plants were initially used to rear the second group of adults as described above. Two plants and one weevil were placed in each of 115 glass tubes $(2.6 \mathrm{~cm}$ in diameter, $20 \mathrm{~cm}$ in length), with 23 replicates for each treatment (but only those adults ovipositing $\geq 8$ days would be subjected to data analysis). Tubes were covered with a plastic screen and kept in the insectary at $26 \pm 1^{\circ} \mathrm{C}$ with a photoperiod of 16:8 (L:D) h. Thereafter, plants were replaced at 3day intervals until adults died; the length of the feeding-scar on old plants was measured with a ruler, and eggs in leaf sheaths were counted under a binocular microscope. For each replicate adult, the cumulative length of the feeding-scar throughout its life, the number of days to first oviposition, days of oviposition and survival, as well as fecundity, were determined.

During the rearing, about three fourths of leaf sheaths in length were submerged in water for oviposition. After plants reached 37 days old, only one plant was used in each replicate.

Feeding and oviposition preference experiment. The preference tests were conducted at 3,9 and 16 days after fertilization treatment, when the plants were 23, 29 and 36 days old, respectively. The adults collected in late-March (the first group) were used. Before being subjected to the tests, adults were reared with rice seedlings (15-20 days old) in the laboratory at $26 \pm 1^{\circ} \mathrm{C}$ for 3 weeks, when they were at the peak-ovipositing stage, as indicated by ovarian dissection and oviposition examination. There were three replicates for each of the three plant ages tested.

In each test, 10 plants in each treatment were randomly selected, and were transplanted to a plastic basin $(75 \mathrm{~cm}$ in diameter, $21 \mathrm{~cm}$ in height) containing ca.10-cm depth of clods, with five hills (spaced at $10-\mathrm{cm}$ each other) and two plants per hill for each treatment. The transplanted plants were arranged in a completely randomized block design. After that, plants were covered with a cylindrical transparent plastic cage $(65 \mathrm{~cm}$ in diameter, $60 \mathrm{~cm}$ in height) whose top was replaced with 
a fine mesh for releasing adults. The plants were left overnight in the insectary at $26 \pm 1^{\circ} \mathrm{C}$ with a photoperiod 16:8 (L:D) h, and then 25 adults were released to the plants. Twenty-four hours after infestation, the cage was removed, and the length of feeding-scars and numbers of eggs on each hill of plants were determined.

Data analysis. The data for feeding, oviposition and survival were subjected to a one-way analysis of variance, and treatment means were separated by Tukey test at $p=0.05$ (SPSS Inc., 1999).

\section{RESULTS}

\section{Feeding and oviposition performance experi- ment}

Nitrogen treatments to rice plants were found to have a significant effect on the feeding amount of L. oryzophilus adults (Table 1). Feeding increased

Table 1. Effects of level of nitrogen fertilization on feeding amount, days to first oviposition, ovipositional period, fecundity and survival period of overwintered L. oryzophilus adults reared on treated rice plants (1-way ANOVA)

\begin{tabular}{lrrr}
\hline \multicolumn{1}{c}{ Observed parameter } & $F$ & df & \multicolumn{1}{c}{$p$} \\
\hline Feeding amount & 39.38 & 4,103 & 0.001 \\
Days to first oviposition & 1.72 & 4,103 & 0.152 \\
Ovipositional period & 50.81 & 4,103 & $<0.001$ \\
Fecundity & 36.10 & 4,103 & $<0.001$ \\
Survival period & 43.18 & 4,103 & $<0.001$ \\
\hline
\end{tabular}

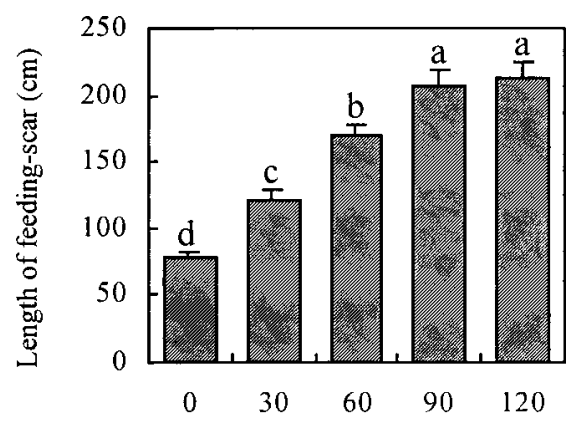

Nitrogen fertilization level ( $\mathrm{kgN} / \mathrm{ha})$

Fig. 1. Mean \pm SE length of feeding scars consumed by overwintered adults of rice water weevil throughout their life on leaves of rice plants treated with different levels of nitrogen fertilizer. Bars with the same letter do not differ significantly $(p<0.05$; Tukey test). Plants were fertilized at 20 days after sowing and initially used the next day. gradually, as expected, when the fertilization increased from 0 to $90 \mathrm{kgN} / \mathrm{ha}$, and reached a plateau at 90 and $120 \mathrm{kgN} / \mathrm{ha}$ (Fig. 1).

Nitrogen fertilization level had no significant effect on the number of days to first oviposition (Table 1, Fig. 2A), but had significant effects on the oviposition period and fecundity (Table 1). The oviposition period increased significantly as fertilization increased from 30 to $60 \mathrm{kgN} / \mathrm{ha}$ and from 60 to $90 \mathrm{kgN} / \mathrm{ha}(p<0.05)$, while it changed little as the fertilization increased further to $120 \mathrm{kgN} / \mathrm{ha}$ (Fig. 2B). The fecundity displayed a similar pattern to the oviposition period as the fertilization in-
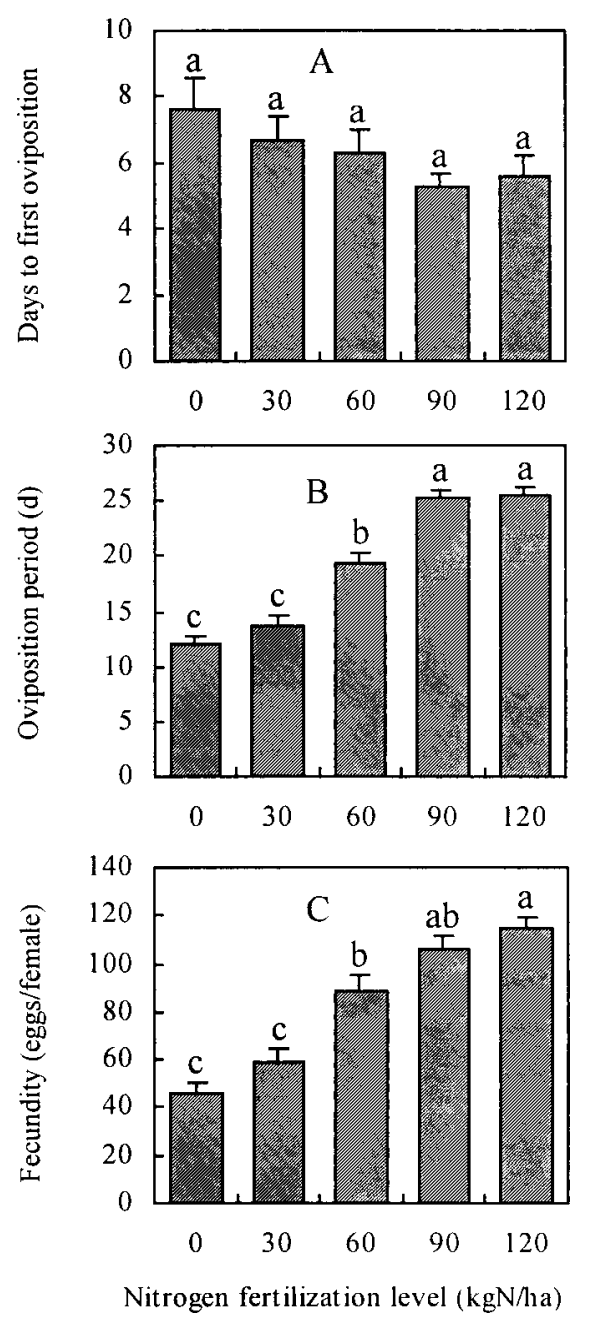

Fig. 2. Mean \pm SE number of days to first oviposition (A), oviposition period (B) and fecundity (C) of overwintered adults of rice water weevil on rice plants treated with different levels of nitrogen fertilizer. Bars with the same letter do not differ significantly $(p<0.05$; Tukey test). At the beginning of rearing, $27 \%$ of adults were at the previtellogenic stage and the others had not initiated reproductive development. 


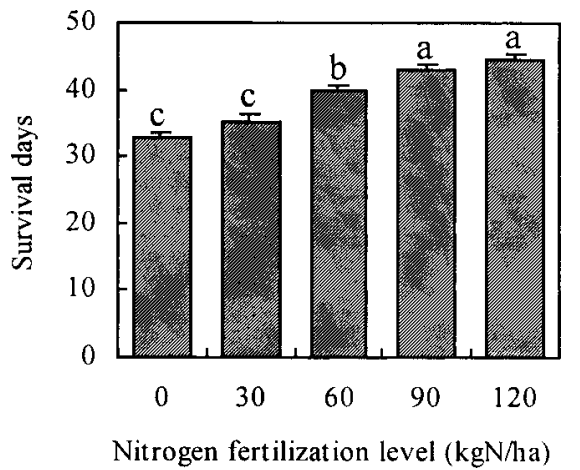

Fig. 3. Mean \pm SE survival days of overwintered adults of rice water weevil on rice plants treated with different levels of nitrogen fertilizer. Bars with the same letter do not differ significantly $(p<0.05$; Tukey test).

creased (Fig. 2C), except that the increase in fecundity was statistically not significant as fertilization increased from 60 to $90 \mathrm{kgN} / \mathrm{ha}(p>0.05)$.

The fertilization had a significant effect on the survival period (Table 1). In the range 30 $90 \mathrm{kgN} / \mathrm{ha}$, the higher the fertilization dose, the significantly longer the adults lived (Fig. 3). The survival period was lengthened further as fertilization increased from 90 to $120 \mathrm{kgN} / \mathrm{ha}$, but the difference was not statistically significant.

\section{Feeding and oviposition preference experiment}

Overall, the length of the feeding scar was significantly affected by fertilization at each of the three plant ages (for 23-, 29- and 36-d-old plants, $F=9.26 ; \mathrm{df}=4,14 ; p=0.002, F=42.93 ; \mathrm{df}=4,14$; $p<0.001$, and $F=86.01 ; \mathrm{df}=4,14 ; p<0.001$, respectively). When 23-d-old plants were provided, more feeding occurred on those fertilized at $120 \mathrm{kgN} / \mathrm{ha}$, but the difference with the treatments 60 and $90 \mathrm{kgN} / \mathrm{ha}$ was not significant $(p>0.05)$. For 29-d-old plants, significantly more preference was showed for the plants fertilized at $60 \mathrm{kgN} / \mathrm{ha}$ than for those at 90 and $120 \mathrm{kgN} / \mathrm{ha}(p<0.05)$, however, the results were strikingly reversed on the 36-d-old plants (Fig. 4A).

The oviposition preference was significantly affected by fertilization at each of the three plant ages (for 23-, 29- and 36-d-old plants, $F=21.55$; $\mathrm{df}=4,14 ; p<0.001, F=5.76 ; \mathrm{df}=4,14 ; p=0.011$, and $F=8.58 ; \mathrm{df}=4,14 ; p=0.003$, respectively). When 23-d-old plants were used, the preference was significantly greatly for plants fertilized at $60 \mathrm{kgN} / \mathrm{ha}$ than for those fertilized at the other
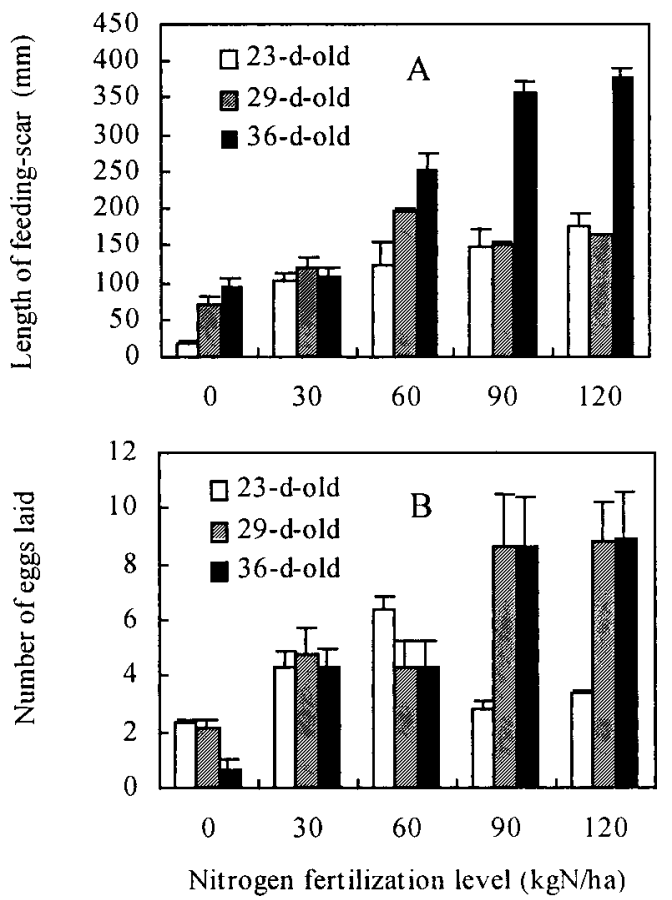

Fig. 4. Mean \pm SE length of feeding scars consumed (A) and number of eggs laid (B) by overwintered adults of rice water weevil during a 24-h rearing on rice plants treated with different levels of nitrogen fertilizer and 23, 29 and 36 days old, respectively. Adults were at peak-ovipositing stage before initiation of the experiments.

levels $(p<0.05)$. While for the 29- and 36-d-old plants, those fertilized at 90 and $120 \mathrm{kgN} / \mathrm{ha}$ were significantly more favored for oviposition $(p<0.05)$ (Fig. 4B).

\section{DISCUSSION}

Nitrogen fertilization can enhance plant quality for most insects by increasing nitrogen levels in plant tissues (McNeill and Southwood, 1978). In the present study, the increased fecundity as well as enhanced feeding and oviposition preference in $L$. oryzophilus with increasing nitrogen fertilization were probably attributed to this nutritional factor. Reduced fecundity due to decreased foliar nitrogen of hosts has been reported in other leaf-feeding weevils. Maier (1983) found that egg laying by the two-banded Japanese weevil, Callirhopalus bifasciatus, decreased as foliar nitrogen reduced. Hesjedal (1984) also found that fecundity of the vine weevil, Otiorhynchus sulcatus, was significantly reduced when the foliar nitrogen content of 
strawberry cultivar Senga Sengana decreased from $2.2 \%$ to $2.0 \%$ of dry leaf matter.

Interestingly, as provided with 29 -d-old plants, L. oryzophilus adults preferred to feed on the plants fertilized at $60 \mathrm{kgN} / \mathrm{ha}$ than on those fertilized at higher levels (Fig. 4A). This suggests that, apart from nitrogen content, other physical or biochemical factors of plants may have been used by the weevil to decide whether or not to feed on a plant. In other weevils whose adults feed on host leaves, feeding selection has been shown to be negatively correlated with density of pubescences on plant leaves (Otiorhynchus sulcatus) (Doss et al., 1991) and leaf toughness (C. bifasciatus) (Maier, $1983)$, and is possibly affected by leaf volatiles $(O$. sulcatus) (Van Tol and Visser, 2002). For the rice water weevil, however, little is known about the associated factors as well as their correlation with nitrogen fertilization.

Besides the factors described above, the biomass of rice plants, including the number of tillers, length of leaf-blades and width of leaf-sheath, may also affect L. oryzophilus feeding and/or oviposition preference. In the present study, it was possible that the greater adult feeding and oviposition preference for the 36-d-old plants fertilized at 90 and $120 \mathrm{kgN} /$ ha (Fig. 4A) partially resulted from increased plant biomass as compared with the situation at lower fertilization levels. As to underlying mechanisms, firstly, increased plant tillers due to elevated fertilization might have increased the probability of adults finding these plants. Secondly, longer leaf-blades and wider leaf-sheaths provided more space for the adult feeding and oviposition, respectively, and might reduce the intraspecific competition associated with these two and other adult behaviors.

Nitrogen fertilization is one of the most important cultural practices for rice. The present study shows that feeding amount, fecundity, as well as feeding and oviposition preference of $L$. oryzophilus adults reached nearly the maximum level as fertilization increased to $90 \mathrm{kgN} / \mathrm{ha}$ (Fig. 1, Fig. 2C, Fig. 4). Therefore, such fertilizations at the rates $\geq 90 \mathrm{kgN} /$ ha should be avoided because they may increase the weevil population and subsequently increase insecticide uses within 1 week after transplantation, which, in turn, would disrupt natural enemies.

However, in some major rice-growing areas of China, such as Zhejiang, Jiangsu and Hunan provinces, nitrogen fertilizers are traditionally highly used $(\geq 100 \mathrm{kgN} / \mathrm{ha})$ as basal fertilizers within 7 days after transplantation, accounting for $55-85 \%$ of the total used during the whole season (Peng et al., 2002; Zhang and Wang, 2002). A reduction in nitrogen fertilization by $30 \%$ at an early stage of rice growth has been suggested, which would not decrease rice yield significantly (Peng et al., 2002). Therefore, in China, there is a great potential for reducing nitrogen fertilization as a cultural approach for L. oryzophilus control.

Lastly, when considering nitrogen management as a control approach for L. oryzophilus, other factors, such as planting date of rice and water management, should be taken into consideration. Because planting date can determine the sensitive stages of rice whether being encountered by the weevil or not, it would potentially affect the actual efficacy of nitrogen management. Water management can not only affect absorption patterns of nitrogen by plants, but can also affect adult infestation pattern, larval developmental rate and population dynamics of this weevil. Based upon these relationships, both plant date and water management have been regarded as potential control tactics of the weevil in the United States (Morgan et al., 1989; Hesler et al., 1992; Quisenberry et al., 1992; Thompson et al., 1994a, b; Rice et al., 1999). This indicates the opportunity of integrating nitrogen management with other cultural practices to establish a cultural control system of this pest.

\section{ACKNOWLEDGEMENTS}

We thank Mr. Xuehao Zheng, Mrs. Zhizheng Jiang, Mr. Jian $\mathrm{Wu}$ and Mrs. Xiaoxue Li (Plant Quarantine Station of Yueqing, Zhejiang, China) for collecting the insect, and students Hongyue $\mathrm{Hu}$ and Weidong $\mathrm{Zhu}$ for assistance in the laboratory. This research was financially supported by National Basic Research and Development Program (2002CB111403), and Zhejiang Committee of Science and Technology Program (991102275).

\section{REFERENCES}

Banerjee, P. K. (1996) Insecticide application at early stage of rice cropping season may cause brown planthopper resurgence. Environ. Ecol. 14: 985-986.

Chander, S. (1999) Effect of nitrogen and irrigation on the leaffolder, Cnaphalocrosis medinalis (Güenée) infestation in paddy. Shashpa 6(1): 49-51.

Dhandapani, N., P. Balsubramanayan and M. Gopalan (1990) Influence of nitrogen levels and plant populations on the 
incidence of rice stem borer Scirpophaga incertulas Walker. Madras Agric. J. 77: 290-294.

Doss, R. P., C. H. Shanks Jr., T. M. Sjulin and J. K. L. Garth (1991) Evaluation of some Fragaria chiloensis X (F. xananassa) seedlings for resistance to black vine weevil. Sci. Hortic. 48: 233-239.

Hesjedal, K. (1984) Influence of the nitrogen content in strawberry leaves on the fecundity of the vine weevil, Otiorrhynchus sulcatus F. (Coleoptera, Curculionidae). Acta Agric. Scand. 34: 188-192.

Hesler, L. S., A. A. Grigarick, M. J. Oraze and A. T. Palrang (1992) Effects of temporary drainage on selected life history stages of the rice water weevil (Coleoptera: Curculionidae) in California. J. Econ. Entomol. 85: 950956.

Ho, D. T. and J. G. Kibuka (1983) Effect of nitrogen and plant density on rice stem borer infestation in western Kenya. Intl. Rice Res. Newsl. 8(5): 17-18.

Holt, J., D. R. Wareing and G. A. Norton (1992) Strategies of insecticide use to avoid resurgence of Nilaparvata lugens (Homoptera: Delphacidae) in tropical rice: a simulation analysis. J. Econ. Entomol. 85: 1979-1989.

Jiang, M. X. and J. A. Cheng (2003) Effects of starvation and absence of free water on oviposition of overwintered adult rice water weevil, Lissorhoptrus oryzophilus Kuschel (Coleoptera: Curculionidae). Intl. J. Pest Management 49: 89-94.

Lin, Y. B, H. W. Shang, L. F. Lu, X. N. Li, Y. Q. Gu, X. H. Huang and X. Y. Dong (1997) Biological characteristics of Lissorhoptrus oryzophilus in the double cropping paddy rice area. Plant Protect. 23(6): 8-11 (in Chinese with English summary).

Lin, Y. B. and L. Zhao (1998) The occurrence and control of rice water weevil in Zhejiang province. China Rice No. 4: 22-24 (in Chinese).

Maier, C. T. (1983) Influence of host plants on the reproductive success of the parthenogenetic two-banded Japanese weevil, Callirhopalus bifasciatus (Roelofs) (Coleoptera: Curculionidae). Environ. Entomol. 12: 1197-1203.

McNeill, S. and T. R. E. Southwood (1978) The role of nitrogen in the development of insect/plant relationships. In Biochemical Aspects of Plants and Animal Coevolution (J. Harbone ed.). Academic, London, pp. 79-99.

Morgan, D. R., N. P. Tugwell and J. L. Bernhardt (1989) Early rice field drainage for control of rice water weevil (Coleoptera: Curculionidae) and evaluation of an action threshold based upon leaf-feeding scars of adults. $J$. Econ. Entomol. 82: 1757-1759.

Peng, S. B., J. L. Huang, X. H. Zhong, J. C. Yang, G. H. Wang, Y. B. Zou, F. S. Zhang, Q. S. Zhu, R. Buresh and C. Witt (2002) Research strategy in improving fertilizer-nitrogen use efficiency of irrigated rice in China. Sci. Agric. Sinica 35: 1095-1103 (in Chinese with English summary).

Quisenberry, S. S., G. B. Trahan, A. M. Heagler, B. McManus and J. F. Robinson (1992) Effect of water management as a control strategy for rice water weevil (Coleoptera: Curculionidae). J. Econ. Entomol. 85: 1007-1014.

Rekhi, R. S., J. Singh and O. P. Meelu (1985) Effect of green manure and nitrogen on mole rat damage and leaffolder (LF) incidence in rice. Intl. Rice Res. Newsl. 10(1): 26.

Rice, W. C., T. P. Croughan, D. R. Ring, M. A. Muegge and M. J. Stout (1999) Delayed flood for management of rice water weevil (Coleoptera: Curculionidae). Environ. Entomol. 28: 1130-1135.

Samalo, A. P., D. Dash, S. K. Panda, C. R. Satpathy and B. K. Mishra (1990) Effect of source, dose and method of nitrogen application to rice crop on stem borer infestation. Orissa J. Agric. Res. 3: 201-205.

Settle, W. H., H. Ariawan, E. T. Astuti, W. Cahyana, A. L. Hakim, D. Hindayana, A. S. Lestari, Pajarningsih and Sartanto (1996) Managing tropical rice pests through conservation of generalist natural enemies and alternative prey. Ecology 77: 1975-1988.

Shang, H. W., J. A. Cheng, L. F. Lü, Y. B. Ling, B. P. Zhai and L. Zhao (1998) Spread tendency and management strategies of rice water weevil in Zhejiang, China. In Researches on Agricultural Development in 21st Century (J. A. Cheng and W. J. Zhou eds.). Chinese Environmental Science Press, Beijing, pp. 429-433 (in Chinese).

SPSS Inc. (1999) SPSS ${ }^{\circledR}$ Base 9.0 Application Guide. SPSS Inc., Chicago. 412 pp.

Sudhakar, G. K., R. Singh, R. B. Thakur and S. B. Mishra (1993) Influence of levels and sources of nitrogen on the incidence of leaf folder, Cnaphalocrocis medinalis Guen. in different rice varieties. J. Entomol. Res. 17: 141-147.

Sun, R. C. and Z. N. Mao (1996) Rice Water Weevil. Chinese Agricultural Press, Beijing, pp. 7-10 (in Chinese).

Thakur, R. B. and S. S. Mishra (1989) Effect of different levels of nitrogen and some granular insecticides on stem borer and leaf folder incidence in rice. J. Entomol. Res. 13: 121-124.

Thompson, R. A., S. S. Quisenberry, F. K. N'Guessan, A. M. Heagler and G. Giesler (1994a) Planting date as a potential cultural method for managing the rice water weevil (Coleoptera: Curculionidae) in water-seeded rice in southwest Louisiana. J. Econ. Entomol. 87: 1318-1324.

Thompson, R. A., S. S. Quisenberry, G. B. Trahan, A. M. Heagler and G. Giesler (1994b) Water management as a cultural control tactic for the rice water weevil (Coleoptera: Curculionidae) in southwest Louisiana. $J$. Econ. Entomol. 87: 223-230.

Van Tol, R. W. H. M. and J. H. Visser (2002) Olfactory antennal responses of the vine weevil Otiorhynchus sulcatus to plant volatiles. Entomol. Exp. Appl. 102: 49-64.

Zhai, B. P. (1996) Migration and diapause of rice water weevil, Lissorhoptrus oryzophilus Kuschel, in double rice cropping area of Zhejiang province, China. Postdoctoral thesis. Zhejiang University, Hangzhou, China. 113 pp. (in Chinese with English summary).

Zhai, B. P., J. A. Cheng, E. Y. Huang, H. W. Shang, X. H. Zheng, J. A. Wu, Y. J. Fang, W. Q. Xia and X. J. Lu (1997) Population dynamics of rice water weevil in double rice cropping area of Zhejiang province, China. Sci. Agric. Sinica 30(6): 23-29 (in Chinese with English summary).

Zhai, B. P., H. W. Shang, J. A. Cheng and X. H. Zheng (1999) 
Constitution of the autumn population of rice water weevils in double cropping rice area of Zhejiang Province, China. Acta Phytophylacica Sinica 26: 193-196 (in Chinese with English summary).

Zhang, Q. C. and G. H. Wang (2002) Optimal nitrogen application for direct-seeding early rice. Chin. J. Rice Sci.
16: 346-350 (in Chinese with English summary).

Zhu, Z. R. (1999) Population ecology and management strategy of the white-backed planthopper Sogatella furcifera (Horvath) in subtropical rice. Ph.D. dissertation. Nanjing Agricultural University, Nanjing, China. 191 pp. (in Chinese with English summary). 